\title{
СОВЕРШЕНСТВОВАНИЕ ЗАКОНОДАТЕЛЬНОГО ОБЕСПЕЧЕНИЯ СИСТЕМЫ МОНИТОРИНГА ОЦЕНКИ ЭФФЕКТИВНОСТИ ПРИМЕНЕНИЯ НОРМАТИВНЫХ ПРАВОВЫХ АКТОВ
}

\author{
(C) 2021 Ларионова Карина Азатовна \\ аспирант \\ Астраханский государственный университет, Россия, Астрахань \\ E-mail:kar1na@yandex.ru
}

Статья посвящена исследованию вопроса законодательного обеспечения мониторинга оценки эффективности применения нормативных актов, выявлению проблем реализации механизма, представлены перспективы развития правового регулирования организации рассматриваемого вида мониторинга. Предложены и обоснованы направления совершенствования законодательного обеспечения общего механизма повышения эффективности нормативных актов.

Ключевые слова: нормативные правовые акты, эффективность применения правовых актов, совершенствование законодательного обеспечения, мониторинг, правоприменение.

В последнее время все активнее растет число принятия нормативных актов. При этом наиболее частым основанием реализации правотворческой инициативы служит внесение поправок в уже действующие нормативные акты, что может свидетельствовать с одной стороны об их низком качестве, а с другой стороны о ситуативности законотворческого процесса. Указанные факторы повышают роль организации правового мониторинга в целом, и мониторинга эффективности применения правовых актов в особенности.

Актуальность реализации мер, связанных с оценкой эффективности нормативных актов, основана на том, что представленная частота принятия актов автоматически приводит к процессу «зарегулированности», что в свою очередь влечет громоздкость правовой системы в целом [7].

Цель исследования заключается в формировании предложений по совершенствованию законодательного обеспечения системы мониторинга оценки эффективности применения нормативных правовых актов.

Методы используемые в процессе проведения исследования, весьма разнообразны. Инструментом в получении фактического материала послужили традиционные методы материалистической диалектики, формально-логический, системный, сравнительно-правовой, статистический и социологический методы, а также наблюдение, анализ, синтез, аналогия, абстрагирование, моделирование и обобщение.

В настоящее время механизмы, связанные с повышением эффективности функциониро- вания нормативных актов довольно детально проработаны. Систему оценки, в зависимости от стадии «жизни» нормативного акта, можно условно поделить на:

- мониторинг проекта нормативного акта;

- мониторинг нормативного правового акта.

В свою очередь указанные механизмы можно представить в виде подсистем единого организма правового мониторинга. Так мониторинг проектов нормативных актов включает такие составные элементы, как:

- антикоррупционная экспертиза;

- общественное обсуждение;

- оценка регулирующего воздействия;

- правовая экспертиза проектов;

- регистрация правовых актов.

Подсистема мониторинга принятых правовых актов включает в себя:

- антикоррупционная экспертиза;

- оценка фактического воздействия;

- мониторинг правоприменения.

Отдельным элементом системы повышения эффективности функционирования нормативных актов является надзорная оценка. Полномочия на ее осуществление принадлежит судебным инстанциям. В данном случае следует определить, что оценка может быть связана с одной стороны с процессом принятия специализированного акта толкования права, предусматривающего возможность повышения эффективности правовых актов, особенно, в случае, когда из содержания нормативного акта не 
следует однозначность формулировок, которые можно использовать без вспомогательного механизма на практике. С другой стороны, судом в заявительном порядке, может быть принято решение о признании акта недействующим в силу его дефектности (например, противоречия вышестоящим актам).

Особую актуальность, в рамках заявленной темы исследовательской работы, приобретают вопросы мониторинга применения нормативных актов. Именно на стадии правореализационных этапов иллюстрируется возможность эксплуатации норм правового акта, реальных возможностей применения положений нормативного документа в контексте функционирования иных актов, задействованных в урегулировании конкретных правоотношений.

Анализ правоприменения через систему конкретных критериев оценки эффективности позволяет выявить проблемы, сформировать и конкретизировать их в отчете и представить в виде доклада главе государства. Именно на основании указанных документов с учетом их анализа и детальной характеристики выявленных пороков нормативных актов, возможно сконструировать новую норму, позволяющую избежать дефектности уже промониторенных актов.

Тем не менее, несмотря на кажущуюся «идеальность» представленной системы оценки эффективности применения правовых актов, представленный механизм в полном объеме своего потенциала до сих пор не использован. В первую очередь это связано с затяжными сроками осуществления мониторинга, что делает механизм громоздким и неподвижным. Динамичные общественные отношения нуждаются в новых универсальных правовых конструкциях, тогда как сам процесс мониторинга охватывает период нескольких лет. Это не позволяет адекватно реагировать на результаты мониторинга и сводит все усилия к нулю. К тому моменту, когда результаты мониторинга лягут в основу доклада Минюста, возможно, правоотношения, которые нуждались в срочной корректировке дефектного акта, уже требуют разрешения.

И это не единственная сложность в реализации механизма мониторинга оценки эффективности применения нормативных актов. Указ № 657 [2], регламентирующий рассматриваемые процессы, устанавливает возможность организации деятельности по сбору, обобщению, анализу и оценке информации по корректировке нормативных актов, органами исполнительной власти РФ и ее субъектов. Внесение в документ термина «возможность», а не «обязанность» нивелирует все разработанные критерии и показатели эффективности по причине того, что упоминаемые органы не очень горят желанием использовать представленную возможность. По этой причине и с учетом того, что функция по представлению доклада принадлежит Минюсту, весь механизм мониторинга правоприменения, реализованный в соответствии с использованием всех критериев оценки эффективности, сводится лишь к трансляции доклада.

Кроме того, из содержания самого Указа № 657 не следует алгоритм дальнейших действий, которые должны определять последствия итогов организованного мониторинга правоприменения. Последним этапом плана мониторинга является именно доклад о его результатах. Никаких мер реагирования на выявленную проблематику дефектности правовых актов действующее законодательство не содержит.

Еще одним недостатком механизма мониторинга следует считать его плановость. Других вариаций по систематизации организации мониторинга Указ № 657 не содержит. По этой причине и с целью наделения большей подвижностью механизма повышения эффективности правовых актов, реализуемого в форме мониторинга правоприменения, следует включить возможность проведения внепланового мониторинга на постоянной основе.

Следует обратить внимание на то, что сам механизм мониторинга включает довольно много элементов, которые в процессе применения действуют не комплексно и зачастую дублируют друг друга, отсутствует системность и взаимодействие, что автоматически снижает эффективность самого механизма оценки.

Горбачев С.А. и Зудов Ю.В. видят решение проблемы в формировании на федеральном уровне единого подхода к подготовке нормативных правовых актов и их оценке и гармонизации действующих механизмов между собой. Авторский коллектив настаивает на том, что необходимо перейти к пониманию единства процесса законотворчества по принципу «оценка-проектакт-оценка», которое в итоге даст синергетический эффект [7].

Автор находит рациональным предлагаемый вариант повышения эффективности функционирования механизма. Детально его анали- 
зируя предлагается на стадии первоначальной оценки охарактеризовать сформированный социальный заказ, то есть готовность общества к регламентации отношений в представленном виде. На этапе формирования проекта оформляется именно проект нормативного акта с учетом возможного развития всех сфер жизнедеятельности и динамики отношений на национальном, региональном, местном и внешнем контурах. Этап принятия акта довольно подробно регламентирован отечественным законодателем со всеми особенностями процедурных компонентов. Заключительная стадия является наиболее продолжительной и связана с оценкой достижения запланированных результатов принятия нормативного акта, сочетания его реализации с иными правовыми актами, актуальности его в разрезе правоприменительной практики.

Следует отметить, что именно заключительный этап оценки правоприменения является наиболее энергоемким. Необходимо анализировать правовой акт с позиции его применительной способности, самостоятельности в регулировании соответствующих отношений, востребованности, а главное, достижения запланированных результатов. Для того, чтобы использовать возможность наиболее емко представить себе процесс мониторинга оценки применения акта по последнему показателю, то есть достижению результатов, необходимо спрогнозировать ожидаемый эффект от принятия акта по различным показателям. Систематизация этих показателей и должна лечь в основу формирования критериев оценки в процессе мониторинга правоприменения. Однако, по мнению автора, целесообразно наряду с общими показателями, изложенными в Указе № 657, сформировать, в зависимости от регулируемой сферы, дополнительный критериальный набор, который позволил бы подойти индивидуально к системе оценки эффективности применения нормативных актов с целью повышения их качества.

Довольно много ученых говорят о необходимости принятия отдельного федерального закона о нормативных правовых актах, так называемого «закона о законах» [8, 9, 10, 11]. Однако, следует понимать, что в отсутствии заявленной инициативы и разработанного проекта акта, следует руководствоваться имеющимися инструментами. На этом основании следует сформировать предложение о систематизации имеющихся механизмов оценки эффективности, их корректировки и комплексности организации самого процесса. Рационально в процесс систематизации включить достижения цифровых технологий, которые позволят сократить время на поиск заимствований и дублирований в нормативных актах, ускорить процесс анализа судебной практики применения нормативных актов, рассмотреть особенности юрисдикционной досудебной востребованности правового акта, подвергающегося мониторингу.

Переходя к конкретным предложениям о совершенствовании законодательного обеспечения мониторинга оценки эффективности применения нормативных актов следует в первую очередь обратить внимание на системность самого механизма. Мониторинг правоприменения нормативных актов не может существовать в отрыве от всего механизма мониторинга нормативно-правовых актов. В этой связи предлагается систематизировать все имеющиеся инструментарии, консолидировать в единый документ общие элементы и критерии оценки эффективности. Наряду с общими следует выделить специальные критерии, применяемые в зависимости от сферы регулируемых нормативным актом отношений. Кроме того, в общую систему законодательного обеспечения следует включить унифицированные методические материалы по организации мониторинга, а также регламент его осуществления.

Для того, чтобы указанная идея стала жизнеспособной, следует организовать работу по анализу всех ныне существующих инструментариев организации мониторинга правовых актов на наличие дублирования актов в регулировании однородных правоотношений. Так, представленная ранее система антикоррупционного мониторинга имеет формы выражения в организации мониторинга правоприменения, независимая форма такой экспертизы дублируется в форме общественного мониторинга. И таких примеров довольно много. Интерес и одновременно сложность в процессе вызывает тот факт, что одинаковый функционал по организации мониторинга относится к полномочиям различных структур, что порождает разность выводов об эффективности применения акта в связи с использованием разных критериев оценки эффективности. Это может порождать диаметрально противоположные итоги мониторинга и повлечь необоснованные корректировки нормативных актов. 
В этой части следует также обратить внимание и на лиц, функционал которых связан с организацией оценки применения актов. Наиболее рациональным видится необходимость консолидации различных структур с целью формирования наиболее объективных выводов в докладе.

Анализируя полномочия по организации мониторинга, возложенные на Минюст [3], наиболее грамотным видится создание при Министерстве специализированного структурного подразделения, включающего в себя специалистов иных ведомств. Так, правильным бы было включение специалистов от Министерства экономического развития [4], Министерства природных ресурсов [5], Министерства сельского хозяйства [6] и т.д. Включение в рабочую группу должно быть связано с содержательными элементами анализируемого акта, характером отношений, на которые направлено его регулирование, а также сферы ожидаемого эффекта его применения. На этом сновании рационально предложить мобильные группы при наличии постоянных экспертов.

Автор предлагает сформировать не только мобильные группы, но и сделать более подвижным сам механизм мониторинга оценки эффективности применения правовых актов. В этой части правильнее было бы отойти от исключительно плановом подходе к проведению мониторинга и включить в качестве видового разнообразия мониторинга оценки эффективности применения нормативных актов оперативный (связанный со срочным, по основаниям, проведением мониторинга), текущий (возлагаемый на соответствующие органы исполнительной власти и органы местного самоуправления на основании принадлежащих им компетенций), инициативный (на основании представленной инициативы общественности, либо органов) и уже регламентированный плановый мониторинг.

Представленные предложения позволят включить в организацию мониторинга органы исполнительной власти и местного самоуправления, которые в настоящий момент отстраняются от подобных функций, поскольку законодатель видит их лишь возможными, но не обязательными (как для Минюста).

Тем не менее, сформированная ныне практика централизации организации мониторинга Минюстом видится логичной. Минюст должен сохранить функции концентратора мониторинга, разработчика и контролера исполнения регламента мониторинга, правильного применения показателей оценки эффективности в процессе мониторинга применения нормативных актов.

Подводя итоги, следует констатировать наличие недостатков в механизме мониторинга оценки эффективности применения нормативных правовых актов. Представленный подробный анализ механизма позволил сформулировать ряд предложений о необходимости дополнительного консолидированного законодательного обеспечения процесса, расширить обязательный субъектный состав мониторинга, унифицировать систему регламентов мониторинга и откорректировать периодичность организации мониторинга, что позволит сделать механизм более подвижным, отвечающим оперативно на потребности государства, общества, человека.

\section{Библиографический список}

1. Конституция РФ (принята всенародным голосованием) от 12 декабря 1993 г. (с изменениями, одобренными в ходе общероссийского голосования 01.07.2020) // Российская газета от 04.07.2020 г. № 144.

2. Указ Президента Российской Федерации от 20.05.2011 № 657 (ред. от 25.07.2014) «О мониторинге правоприменения в Российской Федерации» // Собрание законодательства РФ. 2011. № 21. Ст. 2930.

3. Указ Президента РФ от 13.10.2004 № 1313 «Вопросы Министерства юстиции Российской Федерации» (ред. от 14.01.2021) // Собрание законодательства РФ. 18.10.2004. № 42. Ст. 4108.

4. Постановление Правительства РФ от 05.06.2008 № 437 «О Министерстве экономического развития Российской Федерации» (ред. 27.02.2021) // Собрание законодательства РФ. 16.06.2008. № 24. Ст. 2867.

5. Постановление Правительства РФ от 11.11.2015 № 1219 «Об утверждении Положения о Министерстве природных ресурсов и экологии Российской Федерации и об изменении и признании утратившими силу некоторых актов Правительства Российской Федерации» (ред. от 24.11.2020) // Собрание законодательства РФ. 23.11.2015. № 47. Ст. 6586.

6. Постановление Правительства РФ от 12.06 .2008 № 450 «О Министерстве сельского хозяйства Российской Федерации» (ред. от 28.12.2020) // Собрание законодательства РФ. 23.06.2008. № 25. Ст. 2983. 
7. Горбачев С.А., Зудов Ю.В. Совершенствование системы оценки нормативных правовых актов Российской Федерации // Мониторинг правоприменения. 2019. № 1 (30). С. 30-38.

8. Ипатов В.Д.Новые институты в нормотворчестве и механизмы их реализации, обеспечивающие совершенствование государственного регулирования // Право.ru. 2019. № 3(59). С. 12-17.

9. Скибин Н.А.Мониторинг как вид правового контроля в системе государственного и муниципального управления // Методы прогнозирования в технике и технологиях. Сборник статей по итогам Международной научно-практической конференции. 2018. С. 29-33.

10. Трутнева Е. С. Стадии проведения мониторинга нормативных актов // Проблемы правового обеспечения устойчивого развития оборонно-промышленного комплекса в современных политических и социальноэкономических условиях. Сборник статей Всероссийской научно-практической конференции. Под научной редакцией А.П. Соколова. 2020. С. 365-369.

11. Черногор Н.Н., Залоило М.В.Совершенствование правового регулирования общественного обсуждения проекта нормативного акта // Право. Журнал Высшей школы экономики. 2018. № 4. С. 74-92. 